\title{
International Portfolio Diversification and Market Linkages in the presence of regime-switching volatility
}

\author{
Thomas Flavin* Ekaterini Panopoulou \\ National University of Ireland, Maynooth
}

\begin{abstract}
We examine if the benefits of international portfolio diversification are robust to time-varying asset return volatility. Since diversified portfolios are subject to common cross-country shocks, we focus on the transmission mechanism of such shocks in the presence of regime-switching volatility. We find little evidence of increased market interdependence in turbulent periods. Furthermore, for the vast majority of time, we show that risk reduction is delivered for the US investor who holds foreign equity.
\end{abstract}

Keywords: Market comovement; International portfolio diversification; Financial market crises; Regime switching.

JEL Classification: F42; G15; C32

\footnotetext{
* Correspondence to: Thomas Flavin, Department of Economics, NUI Maynooth, Maynooth, Co. Kildare, Ireland. Tel: + 3531 7083369, Fax: + 3531 7083934, Email: thomas.flavin@nuim.ie
} 


\section{Introduction}

International portfolio diversification has long been advocated as an effective way to achieve higher risk-adjusted returns than domestic investment alone. The main premise underlying this strategy is that international stocks tend to display lower levels of co-movement than stocks trading on the same market. To the extent that countries are subject to different shocks, then international diversification facilitates risk sharing among global investors. Idiosyncratic shocks may be diversified away. Thus investors who pursue cross-country diversification strategies may eliminate country-specific risks but remain vulnerable to common shocks. Therefore the realization and magnitude of portfolio diversification benefits depends crucially on the relative size, frequency and persistence of idiosyncratic and common shocks.

Empirical evidence in support of the pre-eminence of international diversification strategies extends back to Grubel (1968) and Levy \& Sarnat (1970). More recent empirical papers find that these benefits are still present despite increasing integration across financial markets in both stock markets (Grauer and Hakansson, 1987; De Santis and Gerard, 1997) and bond markets (Levy and Lerman, 1988) and in the face of time-varying correlations (Ang and Bekaert, 2002). However, a worrying development for portfolio managers who adopted such a strategy came from the work of King and Wadhwani (1990), who found that stock market correlations between the US, UK and Japan increased in the aftermath of the 1987 stock market crash. Lee and Kim (1993) and Longin and Solnik (1995) both show that this finding also applied to a wider range of countries. These findings have major implications for portfolio management given that if markets display increased comovement during turbulent periods, then the benefits of international diversification will not be delivered when most necessary. Studies like King and Wadhwani (1990) measured the effects of contagion as increased correlation between markets. However, Forbes and Rigobon (2002) showed that when markets experience increased volatility (as in turbulent periods), then the correlation measure is biased upwards and may lead to an incorrect conclusion of financial market contagion. Goetzmann et al (2002) show that episodes of increased cross-market correlation over 
the past two decades may not only be due to increased co-movement alone but also to an expansion of the investment opportunity set.

We focus on whether or not the benefits of portfolio diversification are robust to changes in volatility between calm and turbulent equity market regimes. Since diversified portfolios are subject to common cross-country shocks, we focus on the transmission mechanism of such shocks in an environment characterized by regimeswitching volatility. If the process governing the diffusion of common shocks is stable between regimes, then the diversified portfolio should still out-perform the undiversified, even though everybody does worse in an absolute sense.

We examine the benefits of portfolio diversification that accrue to a representative US investor who considers international investment opportunities across the other G-7 countries. We adopt the methodology of Gravelle et al (2006, henceforth GKM) to provide (as discussed below) an unambiguous test of structural changes in asset return co-movements between regimes. ${ }^{1}$ To the best of our knowledge, no other study has employed this innovative technique to study the transmission of stock market shocks. This method has many advantages over and above previous techniques employed to examine asset market comovement. Firstly, the country where the shock originated does not need to be identified or included in the analysis. Hence we can focus on the G-7 countries and detect changes in the transmission of shocks that may have originated elsewhere. This is going to particularly beneficial in the latter part of our sample when the Asian and Russian crisis occurred. Studies that focus on market contagion tend to concentrate on smaller markets that are geographically close to the source of the shock but we believe that a portfolio manager will be more concerned with the co-movements of the larger countries that typically get included in asset allocation strategies due to their size and diversity. The G-7 countries account for approximately $80-85 \%$ of the total world market capitalization and consequently should constitute the majority of a portfolio regardless of the investor's location. Secondly, the break points of this regime switching procedure are determined by the data and do not have to be exogenously specified as in Forbes and Rigobon (2002). The exogenous choice of crisis period is

\footnotetext{
${ }^{1}$ GKM use the term 'shift contagion' to describe this phenomenon. We use the more general term of 'increased asset comovement between regimes' to reflect the fact that changes may arise due to factors other than purely contagious effects. However, both approaches are technically identical.
} 
often a contentious issue (see Kaminsky and Schmukler, 1999) and may be further compounded by having more than one shock simultaneously impacting on equity markets. Thirdly, our results give us a clear insight into the economic and statistical significance of whether or not a portfolio manager should be concerned with the effects of increased market co-movement between high- and low-volatility regimes.

Our paper is organized as follows. Section 2 presents our model. Section 3 describes the data and presents our preliminary statistics. Section 4 reports our empirical findings and the statistical tests for changes in the transmission of structural shocks. The economic significance of our results is investigated in Section 5 while section 6 examines the robustness of our results by analysing returns expressed in their local currency. Section 7 summarizes our empirical findings and offers some policy implications.

\section{Econometric Methodology}

In this section, we present the empirical model employed to study the interdependence between two stock markets during both calm and turbulent periods. Let $r_{1 t}$ and $r_{2 t}$ represent stock market returns from countries 1 and 2, respectively. These can be decomposed into an expected component, $\mu_{i}$, and an unexpected one, $u_{i t}$, reflecting unexpected information becoming available to investors, i.e.

$$
r_{i t}=\mu_{i}+u_{i t}, E\left(u_{i t}\right)=0, i=1,2 \text { and } E\left(u_{1 t}, u_{2 t}\right) \neq 0 .
$$

The existence of contemporaneous correlation between the forecast errors $u_{1 t}$ and $u_{2 t}$ suggests that common structural shocks are driving both returns. In this respect, we can decompose the forecast errors into two structural shocks, one idiosyncratic and one common. Let $z_{c t}$ and $z_{i t}, i=1,2$ denote the common and idiosyncratic common shocks respectively and let the impacts of these shocks on asset returns be $\delta_{c i t}$ and $\delta_{i t}, i=1,2$. Then the forecast errors are written as:

$$
u_{i t}=\delta_{c i t} z_{c t}+\delta_{i t} z_{i t}, i=1,2 .
$$

Following GKM we allow both the common and the idiosyncratic shocks to switch between two states - high- and low-volatility. ${ }^{2}$ Thus, the structural impact

2 This heterogeneity in the heteroskedasticity of the structural shocks ensures the identification of our system (see also Rigobon, 2003). As argued by GKM, only the 
coefficients $\delta_{i t}, \delta_{c t}, i=1,2$ are given by the following:

$$
\begin{gathered}
\delta_{i t}=\delta_{i}\left(1-S_{i t}\right)+\delta_{i}^{*} S_{i t}, i=1,2 \\
\delta_{c i t}=\delta_{c i}\left(1-S_{c t}\right)+\delta_{c i}^{*} S_{c t}, i=1,2
\end{gathered}
$$

where $S_{i t}=(0,1), i=1,2, c$ are state variables that take the value of zero in normal times and one in turbulent states. Variables with an asterisk belong to the highvolatility or turbulent regime. To complete the model, we need to specify the evolution of regimes over time. Following the regime-switching literature, the regime paths are Markov switching and consequently are endogenously determined. Specifically, the conditional probabilities of remaining in the same state, i.e. not changing regime are defined as follows:

$$
\begin{aligned}
& \operatorname{Pr}\left[S_{i t}=0 / S_{i t}=0\right]=q_{i}, i=1,2, c \\
& \operatorname{Pr}\left[S_{i t}=1 / S_{i t}=1\right]=p_{i}, i=1,2, c
\end{aligned}
$$

Furthermore, we relax the assumption of constant expected returns in (1). ${ }^{3}$ Our specification allows returns to be time varying and dependent only on the state of the common shock. ${ }^{4}$ In this respect, our model suggests that part of the stock market return represents a risk premium that changes with the level of volatility. In particular, expected returns are modeled as follows:

$$
\mu_{i t}=\mu_{i}\left(1-S_{c t}\right)+\mu_{i}^{*} S_{c t}, i=1,2
$$

Given that idiosyncratic shocks are uncorrelated with common shocks and mainly associated with diversifiable risk, expected returns are not allowed to vary with the volatility state of these shocks. An additional assumption of normality of the structural shocks enables us to estimate the full model, given by equations (1)-(4), via maximum likelihood following the methodology for Markov-switching models described in Hamilton (1989).

Our rationale behind detecting and testing for increased comovement due to changes in the transmission of the common shock (see also GKM) lies on the assumption that in its absence, a large unexpected shock that affects both countries does not change their interdependence. In other words, the observed increase in the variance and correlation of returns during turbulent periods is due to increased

assumption of regime switching in the common shocks is necessary for the identification of the system. For a detailed description of the identification process, please see GKM.

${ }^{3} \mathrm{GKM}$ also relax this assumption when modeling the interdependence of bond returns.

${ }^{4}$ Guidolin and Timmermann (2005) find that returns are statistically different across regimes though Ang and Bekaert (2002) fail to reject the equality of mean returns between regimes. 
impulses stemming from the common shocks and not from changes in the propagation mechanism of shocks. To empirically test for this increased interdependence, we conduct hypothesis testing specifying the null and the alternative as follows:

$$
H_{0}: \frac{\delta_{c 1}^{*}}{\delta_{c 2}^{*}}=\frac{\delta_{c 1}}{\delta_{c 2}} \text { versus } H_{1}: \frac{\delta_{c 1}^{*}}{\delta_{c 2}^{*}} \neq \frac{\delta_{c 1}}{\delta_{c 2}}
$$

The null hypothesis postulates that in the absence of increased comovement, the impact coefficients in both calm and turbulent periods move proportionately and hence their ratio should remain unchanged. This likelihood ratio test is the common test for testing restrictions among nested models and follows a $x^{2}$ distribution with one degree of freedom corresponding to the restriction of equality of the ratio of coefficients between the two regimes.

\section{Data and Preliminary Statistics}

Our dataset comprises weekly closing stock market indices from the stock exchanges of the G-7 countries. All indices are value-weighted, obtained from Datastream International, and cover approximately $80 \%$ of total market capitalization. The Datastream codes for the stock market indices have the following structure: TOTMKXX, where XX stands for the country code, i.e. CN (Canada), FR (France), BD(Germany), IT (Italy), JP (Japan), UK and US. The indices span a period of more than 30 years from 1/1/1973 to 31/12/2005, a total of 1723 observations and are expressed in a common currency, namely US dollars. The denomination of the series in US dollars allows us to examine the benefits of portfolio diversification from the perspective of a representative US investor who allocates funds across G-7 equity markets. Moreover, we prefer weekly return data to higher frequency data, such as daily returns, in order to account for the non-synchronous trading in the countries under examination. For each index, we compute the return between two consecutive trading days, $t-1$ and $t$ as $\ln \left(p_{t}\right)-\ln \left(p_{t-1}\right)$ where $p_{t}$ denotes the closing index on week $t$.

\section{[TABLE 1 ABOUT HERE]}

Table 1 (Panel A) presents descriptive statistics for the weekly returns of all countries, while Panel B provides some preliminary evidence on the cross- country return correlation structure. Mean returns vary across countries ranging from $0.139 \%$ 
in Canada to $0.173 \%$ in France. The Japanese market displays the highest volatility among the G-7 countries, while the US and Canadian markets appear to be the least volatile for the US investor. The Jarque-Bera test rejects normality for all markets, which is usual in the presence of both skewness and excess kurtosis. Specifically, return distributions are negatively skewed for all countries with Canada and the US being the most skewed. The Canadian, UK and US returns exhibit considerable leptokurtosis with the coefficient of kurtosis exceeding 10. These attributes of the data should be accommodated in any model of equity returns. The high level of kurtosis coupled with the rejection of normality in all markets may suggest that the behavior of returns is best modelled as a mixture of distributions, which is consistent with the existence of more than one volatility regime.

Panel B provides preliminary evidence on the correlation structure between country returns. Correlation coefficients range from 0.205 for the Italy/Japan pair to 0.705 for the Canada/US pair. The average correlation is 0.408 . Pairs involving either Japan or Italy tend to have below average correlations, while near neighbors such as France/Germany, US/Canada and long established markets such as US/UK have the highest recorded correlations. It is generally found that cross-country correlations are lower than those of domestic stocks. This observation goes back to Grubel and Fadnar (1971), who report that industries within a country are more highly correlated than industries across countries

\section{Results}

\section{$4.1 \quad$ Estimates}

Table 2 reports the estimates of model parameters for the expected returns. Specifically, columns 2 and 3 report the mean returns during calm periods and the corresponding figures for turbulent periods are reported in columns 4 and 5 .

[TABLE 2 ABOUT HERE]

This Table presents us with a number of striking features. Firstly, the low volatility regime is predominantly characterised with positive mean returns. Furthermore all of the means are statistically significant at conventional levels. On the contrary, high volatility regimes are associated with negative returns in all cases, though admittedly, many of these are not statistically different from zero. Therefore a feature 
of the returns behaviour is that crisis (or turbulent) periods generate negative returns to investors. Secondly we compute a likelihood ratio statistic to test the hypothesis that means are equal across regimes. In the vast majority of cases (17 of 21), this hypothesis is rejected and is consistent with the findings of Guidolin and Timmermann (2005) for UK assets. Consequently, it is important to account for this difference in means across regimes when modelling the behaviour of returns.

[FIGURES 1 \& 2 ABOUT HERE]

As our focus is on portfolio diversification benefits, it is useful to examine the filtered probabilities of being in the high-volatility regime before undertaking further statistical tests. International diversification is likely to be most beneficial if the frequency of the high-volatility regime is greater for idiosyncratic shocks than for the common shock. Figure 1 plots the filtered probabilities of the idiosyncratic shocks being in the high-volatility regime. ${ }^{5}$ With the exception of the UK and US, which show a period of relative tranquillity post 1994, the idiosyncratic shocks are most often in the turbulent state for all countries. Therefore this indicates that there is substantial country-specific risk to diversify. In contrast, the frequency with which the common shock is in the high-volatility state is relatively low. Figure 2 presents the evidence. ${ }^{6}$ Almost all pairs of markets shared high volatility in the aftermath of the 1987 stock market crash - a crisis originating in the US -, but again we find a sustained period of high volatility in the aftermath of the Asian and Russian crises of the late 1990's - despite these countries not being in our sample. This displays an advantage of this methodology, as a simple correlation based approach would not be able to incorporate a crisis originating outside of the sample markets. Combining evidence from Figures 1 and 2, it would seem that there are potential benefits to undertaking international diversification strategies. The frequency of the highvolatility, but diversifiable, idiosyncratic shock is much greater than that of the highvolatility common shock.

\section{[TABLE 3 ABOUT HERE]}

\footnotetext{
${ }^{5}$ The figures presented are generated using country $i$ ( $i$ refers to all non-US states) and the US as the market pair and using the UK as the partner for the US. Similar graphs are available for all pairs and are available upon request.

${ }^{6}$ Once more, the graphs presented are for common shocks with the US. Again, graphs for other pairs are available upon request.
} 
Table 3 presents a more detailed description of our results. Firstly, the column labeled 'Unc Prob' gives us information about how much of the time each pair of markets experience a high-volatility regime for their common shock. It is calculated using the formula $\frac{1-P}{2-P-Q}$, where $P$ is the probability that the respective regime will prevail over two consecutive years, i.e. the transition probability from say the high volatility regime to the same regime. As we can see, it varies from a high of $55 \%$ in the case of Japan and Italy to a low of $0.77 \%$ for Italy and the UK. Without any further analysis, this information is potentially important for a fund manager. The low frequency with which Italy and the UK experience a high-volatility common shock, suggests that these markets rarely suffer bad events simultaneously and hence could be used to provide a hedge against each other's risk. On the other hand, the relatively high frequency of shared market turbulence between Japan and Italy would be worrying for a portfolio manager if, these 'crises' periods led to changes in the transmission of structural shocks. The expected benefits of international diversification would be eroded. The average proportion of time that a pair of markets exhibits high common volatility is $14.3 \%$ (roughly 4.75 years), which yields sufficient observations in the high volatility regime to undertake our analysis.

The column labeled 'Duration' gives the length of time (in years) that a common shock persists - Duration $=\frac{1}{1-P}$. The persistence of the high-volatility regime for the common shock is quite low. On average, across all pairs, this regime persists for 0.23 years (or three months). It ranges from periods of approximately one week for Italy/UK, Italy/France and Italy/Japan to a high of over 1.5 years in the case of US/Japan. However the latter is unusual with the next largest (Germany/US) being little over six months.

The remainder of Table 3 presents our estimates of the impact coefficients of common structural shocks for calm $(\delta)$ and turbulent $\left(\delta^{*}\right)$ times (columns 2-3 and 4-5 respectively) as well as the ratio, $\gamma$, (column 6) which allows us to test for increased comovement due to a common shock. For the low volatility regime, the estimated impact coefficients are quite tightly clustered, ranging from 0.45 to 1.78 . Furthermore all estimates are statistically significantly different from zero. In the calm time period the average impact across pairs of countries is 1.27 with a standard deviation of 0.32 . Turning to the high volatility regime, we see much larger estimates and much more 
dispersion. Here the average of the coefficients is 3.80 with a standard deviation of 1.20. Therefore both the average impact and the dispersion of estimates increase threefold. There is also considerable variation in the volatility impacts across pairs of countries. The impact of a high-volatility common shock for the US/Japan pair causes below average increases for both, while large responses to an equivalent shock are recorded for Italy/UK.

We also report the ratio of the estimated impact coefficients of common structural shocks in the column 6 of Table 3. We construct the following statistic:

$$
\gamma=\max \left\{\left|\frac{\delta_{c 1}^{*} \delta_{c 2}}{\delta_{c 2}^{*} \delta_{c 1}}\right|,\left|\frac{\delta_{c 2}^{*} \delta_{c 1}}{\delta_{c 1}^{*} \delta_{c 2}}\right|\right\} .
$$

This reveals whether or not impact coefficients in the high volatility regime are proportional to their corresponding values in the low volatility regime. A ratio of unity indicates that there is no difference in the transmission mechanism of shocks between the high- and low-volatility regimes, whereas deviations from unity would imply increased market comovements in the turbulent regime. At this point we concentrate on the economic significance of the $\gamma$ ratio but we will later test for its statistical significance.

Even without a formal test, our results suggest that for a large number of country pairs, the transmission mechanism governing common shocks does not experience major changes between high- and low-volatility regimes. Over half of our sample pairs (13 from 21 ) generate ratios of less than 1.05. If this turns out to be statistically significant evidence of increased interdependence, at least it's at a relatively low level. At the other end of the scale, the US/Japan ratio is over 3.3, with seven other pairs generating increases in the ratio in excess of $5 \%$. Ratio values of this magnitude would be of huge concern to a portfolio manager as they indicate adverse movements in stock returns tend to be amplified, thereby reducing expected benefits from international diversification.

It is also worth noting that comparable levels of the ratio can be arrived at in different ways. For example, the pairs Canada/France, Italy/Japan and Germany/Italy all have similar ratios. However, for all three pairs their common shock exerts different influences on stock market volatility. For the Canada/France pair, the volatility for both in turbulent periods is three times that associated with calm periods, while for Italy/Japan and Germany/Italy the corresponding increase 
in market variability is 4.7 and 2.8 times respectively. Despite the ratio being the main focus of our analysis, closer examination of Table 3 will allow the investor to learn more about the process underlying our results.

Before testing for changes in the transmission of a common shock between each pair of markets, we check if our model is appropriate for the asset returns in our analysis. Table 4 reports results from a number of diagnostic tests. Columns 2 and 3 report the LM test for serial correlation in the standardized residuals of the country pairs examined. ${ }^{7}$ In general, for the majority of the country pairs, we cannot reject the null of no serial correlation at both one and four lags. The same conclusion is reached as far as $\mathrm{ARCH}$ effects are considered (see Columns 3 and 4), though when testing for ARCH effects up to fourth order, the percentage of series for which we can reject the null increases to 25 percent. Instead of applying the Jarque Bera statistic, which concentrates on the third and fourth moment, to test for Normality, we test for Normality based on the overall approximation of the empirical distributions of standardized residuals to the Normal by employing the Cramer-von Mises test. Our results, reported in Column 6, suggest that the majority of country residuals are Normally distributed. ${ }^{8}$ This suggests that our two-regime model captures quite well the distribution of asset returns.

\section{[TABLE 4 ABOUT HERE]}

As a measure of our models' regime qualification performance, we employ the Regime Classification Measure (RCM) developed by Ang and Bekaert (2002). RCM is a summary statistic that captures the quality of a model's regime qualification performance. According to this measure, a good regime-switching model should be able to classify regimes sharply, i.e. the smoothed (ex-post) regime probabilities, $p_{t}$ are close to either one or zero. For a model with two regimes, the regime classification measure $(R C M)$ is given by:

$$
R C M=400 * \frac{1}{T} \sum_{t=1}^{T} p_{t}\left(1-p_{t}\right),
$$

where the constant serves to normalize the statistic to be between 0 and 100 . A perfect model will be associated with a RCM close to zero, while a model that cannot

\footnotetext{
${ }^{7}$ Please note that all six sets of standardized residuals are reported for each country.

${ }^{8}$ We also employed the Kolmogorov-Smirnov, Lilliefors, Anderson-Darling, and Watson empirical distribution tests, which yielded similar results. These results are available upon request.
} 
distinguish between regimes will produce a RCM close to 100. The final three columns of Table 4 report the RCM for the two idiosyncratic shocks and the common volatility shock respectively. Using a cut-off of 50 suggests that in most cases, our two-regime model does a good job in describing the asset return generating process. However, it does perform better in capturing the common shock than the idiosyncratic shocks in most pairs.

\subsection{Tests for increased comovement}

In testing for changes in the transmission of a common shock between highand low-volatility regimes, we focus on the ratio $\gamma$, and test whether or not it is statistically different from unity. We perform a likelihood ratio test, whose test statistic has a $\chi^{2}(1)$ distribution under the null hypothesis. Table 5 presents the results.

\section{[TABLE 5 ABOUT HERE]}

The most striking feature of our results is that we find little evidence of any increased comovement. In the majority of cases (19 out of 21), we fail to reject the null hypothesis of no change in the ratio of market responses to a common shock. In other words, we find that the mechanism by which common shocks are transmitted is unaffected by the switch from a low- to high-volatility regime. This is a reassuring result for the proponents of international diversification across equity markets as a means of reducing portfolio risk.

For the other 2 pairs - US/UK and France/Germany - we find evidence that going from a calm financial environment to a period of turbulence generates greater asset return comovement and hence may erode the expected gains from international portfolio diversification. The ratio for the UK/US, though statistically different to unity, is quite low at 1.001 . So even if these large, traditionally strong markets show evidence of changes in the transmission mechanism of the common shock, it is unlikely to deter potential investors from holding the equities of the two countries in their portfolio. On the other hand, the ratio for France/Germany is 1.146, representing quite a large shift in the diffusion process of the common shock. This result may be potentially explained by the proximity of the two markets and their 
close political and economic links. These factors may increase the propagation of common shocks.

\section{Economic significance of portfolio diversification}

Having found little statistical evidence of increased market comovement, we now turn to the economic significance of our results. We first of all investigate the importance of the idiosyncratic shocks that the investor seeks to diversify away. We have already seen in Figure 1, that the idiosyncratic shocks for pairs involving the US tend to be in the high-volatility regime with far greater frequency than the common shock for each corresponding pair. The evidence presented in Table 6 seems to verify this finding for all possible market pairs. Just as in the case of the common shock, we present the proportion of time the idiosyncratic shock spends in the turbulent regime and the persistence of the shock. We find that, on average, the idiosyncratic shock is in the high-volatility state $41.5 \%$ of the time (roughly 13.5 years). This number is almost three times greater than that for the common shock. Likewise, the persistence of the country-specific shock is much greater, with an average of 1.5 years that is approximately 6 times that of the common shock. In columns 2-5, we also report the impact coefficients for the idiosyncratic shocks. There is greater variation in the coefficients with some spectacular increases from calm to turbulent markets, e.g. for the Japan/UK pairing, the impact of the idiosyncratic shock is over 45 times greater for the UK in the high- compared to the low-volatility regime. Thus the evidence presented in Figures $1 \& 2$ and Table 6 indicate that idiosyncratic shocks occur more frequently and display greater persistence than common shocks.

Given that the motivation for undertaking diversification is predominantly one of risk reduction, we compare the risk of a domestic US portfolio with that comprising of US and foreign equity. To accomplish this, we use our model to compute the time-varying covariance matrix. Recall from (2), that the aggregate shock of each country return is decomposed into an idiosyncratic and common shock. Both common and idiosyncratic shocks are allowed to switch between high and low-volatility states, which are assumed to be independent. In this respect, our analysis encompasses 8 states of nature, ranging from the state when all shocks are in the low volatility regime to the one when all shocks display high volatility. Each state is associated with a different variance-covariance matrix, which is uniquely 
calculated on the basis of our model given by (1)-(4). For example, the variance covariance matrices associated with the extreme states are as follows:

$$
\begin{aligned}
& \Sigma_{1}=\left[\begin{array}{cc}
\sigma_{1}^{2}+\sigma_{c 1}^{2} & \sigma_{c 1}{ }^{*} \sigma_{c 2} \\
\sigma_{c 1} \sigma_{c 2} & \sigma_{2}^{2}+\sigma_{c 2}^{2}
\end{array}\right] \\
& \Sigma_{8}=\left[\begin{array}{cc}
\sigma^{* 2}+\sigma^{* 2} & \sigma_{c 1}^{*} \sigma_{c 2}^{*} \\
\sigma_{c 1}^{*} \sigma_{c 2}^{*} & \sigma_{2}^{* 2}+\sigma_{c 2}^{* 2}
\end{array}\right]
\end{aligned}
$$

We compute the time-varying conditional covariance matrix of returns from these state matrices by utilizing the estimated filter probabilities for each type of shock (see Figures 1 and 2). The filter probabilities give the probability of being in each state for each shock given the history of the process up to that point of time. For all countries, we then compare the risk of a US portfolio versus a portfolio with $x \%$ invested in the foreign equity and the remainder in US equity. Figure 3 presents the risk reduction benefits of international portfolio diversification with $10 \%$ of funds invested in the foreign country. Given the relative size of markets and the observed home bias in asset holdings (French and Poterba, 1991; Cooper and Kaplanis, 1994), $10 \%$ is probably a realistic estimate of the foreign asset holdings of US investors. Figure 3 portrays the variance of the internationally diversified portfolio as a proportion of the variance of the US only portfolio. We can see immediately that at this level of foreign asset holding, international diversification delivers considerable reduction in risk for the US investor. The ratio is always less that unity and delivers average risk reduction ranging from $5.5 \%$ for Canadian investment up to $11.5 \%$ for diversification into Italian equity. Furthermore, diversification benefits were large in the aftermath of the 1987 crash when the US investor most needed protection. Table 7 reports the average risk reduction (Panel A) associated with different levels of foreign diversification and the proportion of time (Panel B) when the diversified portfolio was more risky than its domestic counterpart. Again the evidence strongly supports the proponents of diversification across international markets. In general, the average risk reduction increases with the level of diversification. For example, a US investor who allocates her wealth between domestic and Italian assets reaps benefits ranging from a $6.3 \%$ decline in risk for holding $5 \%$ of the portfolio in the foreign equity to a fall of almost $20 \%$ for allocating $25 \%$ of wealth to the Italian asset. Though smaller in magnitude, this pattern is repeated for all countries. Even the UK, 
for which we found a statistically significant increase in its comovement with the US market, delivers risk reduction benefits for all plausible levels of diversification. ${ }^{9}$ Furthermore, Panel B of Table 7, shows us that risk reduction achieved on average, also manifests in the majority of individual time periods. When allocating up to $10 \%$ of the fund to foreign assets, the US investor always enjoys lower portfolio risk. Increasing the allocation to non-domestic equity may reduce average risk but it also produces some periods when the diversified portfolio is more risky. However, the number of such time periods is small and even for funds with $20 \%$ held in foreign assets, the maximum proportion of time that fails to deliver risk reduction is $6 \%$ (for French equity), while investments in Canada, Germany and Italy still deliver lower risk portfolios in every period. Consequently, we conclude that international diversification consistently delivers reduced portfolio risk for US investors.

Therefore, we argue that the benefits of hedging idiosyncratic risks outweigh the burden of bearing common shocks. Idiosyncratic are found to be more frequent, more persistent and larger in magnitude than the common shock. Both our statistical and economic results reinforce the belief that international portfolio diversification strategies are worthwhile and provide the investor with insurance against domestic risk. Our results show that the US investor should allocate funds to international assets and the fear of increased comovement during periods of global market turbulence should not prevent such diversification. Even if everybody loses in an absolute sense, diversification benefits remain sufficiently large to compensate the investor who has spread her risk internationally.

\section{Robustness}

We check the robustness of our statistical results by repeating the analysis for equity returns expressed in their local currency. Though improbable in practice, this is akin to holding a portfolio whereby the foreign exchange rate has been completely eliminated. In Table 8, we report the impact coefficients for the common shock, the ratio measuring changes in the transmission mechanism of the shock and the results

\footnotetext{
${ }_{9}$ Of course, given the bivariate structure of our model, we limit ourselves to two-country diversification. Therefore these numbers may be viewed as lower bounds to the potential benefits available for a multi-country diversification strategy.
} 
of the likelihood ratio test for statistical significance. While we do find more statistical significance of increased comovement, the majority of pairs (13 of 21) still fail to reject the null hypothesis of no change in the transmission mechanism of the common shock. From the perspective of the US investor, only Canada shows evidence of increased interdependence.

Given our results for the common currency returns and that we fail to reject the null hypothesis of no increased comovement for over $60 \%$ of the market pairs expressed in local currency, we conclude that results are generally supportive of the notion that the process governing the diffusion of the common shock is relatively stable between regimes and hence the benefits expected to accrue from international diversification in tranquil markets should also manifest themselves in turbulent market conditions.

\section{Conclusion}

We have focussed on whether or not the benefits to international portfolio diversification are robust to time-varying asset return volatility. If markets exhibit increased comovement during turbulent periods, then the risk-sharing motive behind diversification may fail to deliver the perceived benefits in periods when they are most needed. Investors who diversify do so to eliminate idiosyncratic shocks but remain vulnerable to common shocks. Therefore we concentrate on testing for changes in the transmission mechanism of the common shock. If markets respond in the same way to common shocks during both calm and turbulent conditions, then market comovement should be unaffected and diversification should continue to protect the investor in the high-volatility state. However, if high-volatility regimes are associated with greater levels of interdependence, then such protection may be eroded. We use the methodology introduced by GKM to test for changes in market interdependence. The main advantage of this methodology for our study is that we can test for these changes between countries without having to identify or including the source of the shock. Methodologies that require the market from which the shock emanated to be included, often force studies to concentrate on relatively small or regional markets. In discussing the implications for portfolio selection, we should focus on the larger markets of the world and by choosing the G-7 countries, we cover about $80 \%$ of world market capitalisation. Obviously, these markets will be the 
major recipient of capital inflows and hence vehicles for international portfolio diversification.

We use a regime-switching model to exploit the heteroskedasticity inherent in stock returns to identify whether or not increased comovement occurs between each pair of markets as we move between tranquil and turbulent market conditions. We take the perspective of a US investor and all returns are expressed in dollars. We report a number of interesting findings. Firstly, we find that expected stock returns are statistically different between regimes. Calm markets are associated with significantly positive returns while turbulent markets are characterised as generating negative mean returns. Secondly, our model seems to capture the features of return distributions quite well and we find that common market shocks are, on average, in a high-volatility regime about $23 \%$ of the time. Some market pairs, e.g. Italy and UK, incur few common shocks and consequently are likely to provide risk reduction benefits if held together in portfolios. Thirdly, we find little evidence of changes in the process governing the diffusion of common shocks between the pairs of markets under review. In 90\% (19 of 21) of cases, we fail to reject the hypothesis of no change in the transmission mechanism. Though not as strong, the majority of local currency return pairs are also consistent with this finding.

Having found little statistical evidence of increased comovement, we examine the economic significance of our results. We find that relative to the common shock, the idiosyncratic shocks are more frequently in the high-volatility regime and exhibit more persistence in this state. Hence it appears that the diversifiable risks are greater than common risks and thus favours international diversification. To confirm this, we examine the risk reduction achieved by a US investor who invests a proportion of wealth in a foreign equity market while holding the remainder in domestic equity. For realistic levels of diversification, we find that risk is substantially lower in the vast majority of cases. Even holding one foreign asset can reduce risk of a US portfolio by up to $20 \%$.

Combining our statistical tests and the investigation of the economic importance of our estimates, we find strong support for the adoption of international diversification strategies. There is little evidence that the transmission of common shocks changes between low- and high-volatility regimes. Furthermore, the risk reduction benefits appear to be robust to changes in volatility and indeed were manifest in the aftermath of the 1987 crash when US investors were most vulnerable. 
We show that these benefits can be expected to accrue during both calm and turbulent market conditions. Consequently, this should encourage fund managers to pursue international diversification strategies without fear of potential benefits being eroded during periods of high volatility, such as those associated with bear markets.

\section{Acknowledgements}

We would like to thank Prof. Jerry Dwyer and other seminar participants at the Federal Reserve Bank of Atlanta for helpful comments and suggestions on an earlier draft of this paper. We also thank James Morley for making the Gauss code available to us. 


\section{References}

Ang, A., Bekaert, G., 2002. International asset allocation with regime shifts. Review of Financial studies, 15, 1137-1187.

Cooper, I., Kaplanis E., 1994. Home bias in equity portfolios, inflation hedging, and international capital market equilibrium. Review of Financial Studies, 7, 45-60.

Cramer H., 1928. On the composition of elementary errors, Skandinavisk Aktuarietidskrift, 11, 141-180.

De Santis, G., Gerard, B., 1997. International asset pricing and portfolio diversification with time-varying risk. Journal of Finance 52 (5), 1881-1912.

Forbes, K.J., Rigobon, R.J., 2002. No contagion, only interdependence: measuring stock market comovements. Journal of Finance, 57 (5), 2223-61.

French, K.R., Poterba J.M., 1991. Investor diversification and international equity markets. American Economic Review, 81(2), 222-226.

Goetzmann, W., Li, L., Rouwenhorst, K.G., 2002. Long-term global market correlations. Working Paper no. 8612, National Bureau of Economic Research, Cambridge, MA.

Gravelle, T., Kichian, M., Morley, J., 2006. Detecting shift-contagion in currency and bond markets. Journal of International Economics, 68(2), 409-423.

Grubel, H., 1968. Internationally diversified portfolios: welfare gains and capital flows. American Economic Review 58, 1299-1314.

Grubel, H., Fadnar, K., 1971. The interdependence of international equity markets. Journal of Finance 26 (1), 89-94.

Guidolin, M., Timmermann, A., 2005. Economic implications of bull and bear regimes in UK stock and bond returns, Economic Journal, 115, 111-143.

Hamilton, J.D., 1989. A new approach to the economic analysis of nonstationary time series and the business cycle, Econometrica, 57, 357-384.

Kaminsky, G.L., Schmukler, S.L., 1999. What triggers market jitters? A chronicle of the Asian crisis. Journal of International Money and Finance, 18, 537-560.

King, M.A., Wadhwani, S., 1990. Transmission of volatility between stock markets. Review of Financial Studies, 3, 5-33.

Lee, S.B., Kim, K.J., 1993. Does the October 1987 crash strengthen the co-movements among national stock markets? Review of Financial Economics, 3, 89-102.

Levy, H., Lerman, Z., 1988. The benefits of international diversification in bonds. Financial Analysts Journal, 44, 56-64. 
Levy, H., Sarnat, M., 1970. International diversification of investment portfolios.

American Economic Review 60, 668-675.

Longin, F., Solnik, B., 1995. Is the correlation in international equity returns constant: 1960 - 1990? Journal of International Money and Finance, 14, 3-26.

Rigobon, R., 2003. Identification through heteroskedasticity. The Review of Economics and Statistics, 85(4), 777-792. 
Table 1: Summary Descriptive Statistics

Panel A: Full sample US dollars (1/1/73-31/12/2005)

\begin{tabular}{lccccccc}
\hline \hline & Canada & France & Germany & Italy & Japan & UK & US \\
\hline \hline Mean & 0.139 & 0.173 & 0.150 & 0.150 & 0.132 & 0.146 & 0.141 \\
Median & 0.236 & 0.288 & 0.246 & 0.000 & 0.186 & 0.194 & 0.294 \\
Maximum & 12.862 & 12.448 & 12.225 & 15.772 & 14.824 & 22.346 & 12.302 \\
Minimum & -24.492 & -19.214 & -15.032 & -18.605 & -21.361 & -24.357 & -27.090 \\
Std. Dev. & 2.312 & 2.946 & 2.608 & 3.010 & 3.519 & 2.735 & 2.300 \\
Skewness & -0.932 & -0.462 & -0.504 & -0.031 & -0.174 & -0.141 & -1.050 \\
Kurtosis & 11.916 & 5.752 & 5.676 & 5.379 & 4.842 & 10.759 & 15.779 \\
Jarque- Bera & 5952.841 & 604.682 & 586.868 & 406.267 & 252.181 & 4324.721 & 12033.400 \\
\hline \hline
\end{tabular}

\begin{tabular}{cccccccc}
\hline \multicolumn{7}{c}{ Panel B: Correlations } \\
\hline Market & Canada & France & Germany & Italy & Japan & UK & US \\
\hline Canada & 1.000 & 0.437 & 0.434 & 0.301 & 0.282 & 0.468 & 0.705 \\
France & & 1.000 & 0.625 & 0.339 & 0.408 & 0.525 & 0.437 \\
Germany & & & 1.000 & 0.367 & 0.422 & 0.488 & 0.432 \\
Italy & & & 1.000 & 0.205 & 0.318 & 0.282 \\
Japan & & & & 1.000 & 0.366 & 0.278 \\
UK & & & & & 1.000 & 0.456 \\
US & & & & & & 1.000 \\
\hline \hline
\end{tabular}


Table 2. Estimates of mean returns across regimes

\begin{tabular}{|c|c|c|c|c|c|c|}
\hline Country pairs & $\mu_{1}$ & $\mu_{2}$ & $\mu_{1}^{*}$ & $\mu_{2}^{*}$ & $L R$ & $p$-val \\
\hline \multirow[t]{2}{*}{ Canada/US } & 0.199 & 0.216 & -0.760 & -0.427 & $4.738^{*}$ & 0.094 \\
\hline & $(0.049)$ & $(0.047)$ & $(0.677)$ & $(0.659)$ & & \\
\hline \multirow[t]{2}{*}{ France/US } & 0.306 & 0.232 & -0.596 & -0.425 & $7.703^{* *}$ & 0.021 \\
\hline & $(0.061)$ & $(0.046)$ & $(0.195)$ & $(0.172)$ & & \\
\hline \multirow[t]{2}{*}{ Germanu/US } & 0.282 & 0.230 & -0.390 & -0.124 & $7.476^{* *}$ & 0.024 \\
\hline & $(0.058)$ & $(0.047)$ & $(0.138)$ & $(0.150)$ & & \\
\hline \multirow[t]{2}{*}{ Italu/US } & 0.243 & 0.221 & -0.720 & -0.367 & $8.491^{* *}$ & 0.014 \\
\hline & $(0.067)$ & $(0.048)$ & $(0.291)$ & $(0.309)$ & & \\
\hline \multirow[t]{2}{*}{ Iapan/US } & 0.251 & 0.220 & -0.176 & -0.006 & $6.216^{* *}$ & 0.045 \\
\hline & $(0.101)$ & $(0.051)$ & $(0.246)$ & $(0.096)$ & & \\
\hline \multirow[t]{2}{*}{ UK/US } & 0.214 & 0.204 & -0.590 & -0.309 & 4.513 & 0.105 \\
\hline & (0.057) & (0.049) & $(0.284)$ & $(0.327)$ & & \\
\hline \multirow[t]{2}{*}{ Canada/UK } & 0.213 & 0.203 & -0.876 & -0.750 & $5.099^{*}$ & 0.078 \\
\hline & $(0.051)$ & $(0.058)$ & $(0.645)$ & $(0.627)$ & & \\
\hline \multirow[t]{2}{*}{ France/UK } & 0.328 & 0.254 & -0.835 & -0.511 & $11.579 * * *$ & 0.003 \\
\hline & $(0.066)$ & $(0.058)$ & $(0.364)$ & $(0.320)$ & & \\
\hline \multirow[t]{2}{*}{ Germanu/UK } & 0.255 & 0.186 & -0.606 & -0.195 & $8.295^{* *}$ & 0.016 \\
\hline & $(0.055)$ & $(0.056)$ & (0.389) & $(0.269)$ & & \\
\hline \multirow[t]{2}{*}{ Italu/UK } & 0.168 & 0.239 & -4.142 & -4.664 & 2.221 & 0.329 \\
\hline & $(0.075)$ & $(0.062)$ & $(0.666)$ & $(0.821)$ & & \\
\hline \multirow[t]{2}{*}{ Iapan/UK } & 0.189 & 0.231 & -0.839 & -0.676 & $7.764^{* *}$ & 0.021 \\
\hline & $(0.078)$ & $(0.056)$ & $(0.377)$ & $(0.422)$ & & \\
\hline \multirow[t]{2}{*}{ Canada/Iapan } & 0.229 & 0.160 & -1.171 & -0.980 & $6.887^{* *}$ & 0.032 \\
\hline & $(0.044)$ & $(0.070)$ & (1.404) & (1.591) & & \\
\hline \multirow[t]{2}{*}{ France/Iapan } & 0.316 & 0.215 & -0.698 & -0.568 & $7.312^{* *}$ & 0.026 \\
\hline & $(0.065)$ & $(0.076)$ & $(0.325)$ & $(0.314)$ & & \\
\hline \multirow[t]{2}{*}{ Germanu/Iapan } & 0.258 & 0.189 & -0.529 & -0.320 & $7.551^{* *}$ & 0.023 \\
\hline & $(0.057)$ & $(0.075)$ & $(0.257)$ & $(0.219)$ & & \\
\hline \multirow[t]{2}{*}{ Italu/Iapan } & -0.112 & 0.619 & 0.313 & -0.195 & $9.150^{* * *}$ & 0.010 \\
\hline & $(0.208)$ & $(0.194)$ & (0.196) & $(0.187)$ & & \\
\hline \multirow[t]{2}{*}{ Canada/Italu } & 0.212 & 0.196 & -1.260 & -0.615 & 3.776 & 0.151 \\
\hline & $(0.049)$ & $(0.060)$ & $(0.518)$ & $(0.065)$ & & \\
\hline \multirow[t]{2}{*}{ France/Italu } & 0.416 & 0.093 & -2.767 & 1.004 & $5.161^{*}$ & 0.076 \\
\hline & $(0.081)$ & $(0.153)$ & $(0.817)$ & $(0.782)$ & & \\
\hline \multirow[t]{2}{*}{ Germanu/Italu } & 0.283 & 0.177 & -0.657 & -0.006 & $8.644^{* *}$ & 0.013 \\
\hline & $(0.060)$ & $(0.066)$ & $(0.287)$ & $(0.013)$ & & \\
\hline \multirow[t]{2}{*}{ Canada/Germanu } & 0.209 & 0.230 & -0.584 & -0.919 & $7.184^{* *}$ & 0.028 \\
\hline & $(0.051)$ & $(0.058)$ & (1.013) & (1.212) & & \\
\hline \multirow[t]{2}{*}{ France/Germanu } & 0.274 & 0.272 & -0.160 & -0.248 & 4.536 & 0.104 \\
\hline & $(0.062)$ & $(0.056)$ & $(0.180)$ & $(0.174)$ & & \\
\hline Canada/France & 0.229 & 0.293 & -0.742 & -1.015 & $9.135^{* *}$ & 0.010 \\
\hline
\end{tabular}

Notes: Standard errors in parentheses below coefficients. Likelihood ratio statistic is for the null of equality of mean returns across the regimes. The test statistic has a $\chi^{2}(2)$ distribution under the null hypothesis. ${ }^{* * *}$ denotes significance at $1 \%$ level, ${ }^{* *}$ denotes significance at $5 \%$ level, and ${ }^{*}$ denotes significance at $10 \%$ level. 
Table 3. Estimates of impact coefficients of common shocks

\begin{tabular}{|c|c|c|c|c|c|c|c|}
\hline Country pairs & $\delta_{c 1}$ & $\delta_{c 2}$ & $\delta_{c 1}^{*}$ & $\delta_{c 2}^{*}$ & $r$ & Unc. Prob. & Duration \\
\hline \multirow[t]{2}{*}{ Canada/US } & 1.453 & 1.523 & 4.284 & 4.482 & 1.001 & $7.05 \%$ & 0.12 \\
\hline & $(0.099)$ & $(0.104)$ & $(0.441)$ & $(0.479)$ & & & \\
\hline \multirow[t]{2}{*}{ France/US } & 1.124 & 1.370 & 2.941 & 3.914 & 1.092 & $13.12 \%$ & 0.28 \\
\hline & $(0.087)$ & $(0.062)$ & $(0.386)$ & $(0.288)$ & & & \\
\hline \multirow[t]{2}{*}{ Germanu/US } & 0.930 & 0.976 & 2.719 & 2.868 & 1.004 & $21.28 \%$ & 0.54 \\
\hline & $(0.028)$ & $(0.087)$ & (0.199) & $(0.151)$ & & & \\
\hline \multirow{2}{*}{ Italu/US } & 0.720 & 1.130 & 2.398 & 3.765 & 1.000 & $11.02 \%$ & 0.27 \\
\hline & $(0.127)$ & $(0.091)$ & $(0.313)$ & $(0.341)$ & & & \\
\hline \multirow{2}{*}{ Iapan/US } & 1.460 & 0.637 & 1.723 & 2.487 & 3.304 & $30.45 \%$ & 1.57 \\
\hline & $(0.182)$ & $(0.090)$ & $(0.200)$ & $(0.133)$ & & & \\
\hline \multirow[t]{2}{*}{ UKЛUS } & 1.175 & 1.290 & 3.889 & 4.272 & 1.001 & $9.10 \%$ & 0.17 \\
\hline & $(0.120)$ & $(0.103)$ & $(0.381)$ & $(0.400)$ & & & \\
\hline \multirow{2}{*}{ Canada/UK } & 1.367 & 1.211 & 4.384 & 3.883 & 1.001 & $7.09 \%$ & 0.11 \\
\hline & $(0.100)$ & $(0.121)$ & $(0.491)$ & $(0.582)$ & & & \\
\hline \multirow{2}{*}{ France/lK } & 1.599 & 1.471 & 4.183 & 3.846 & 1.001 & $16.02 \%$ & 0.15 \\
\hline & $(0.126)$ & (0.099) & $(0.347)$ & $(0.285)$ & & & \\
\hline \multirow{2}{*}{ Germanu/UK } & 1.502 & 1.266 & 3.879 & 3.303 & 1.011 & $14.90 \%$ & 0.17 \\
\hline & $(0.058)$ & $(0.078)$ & $(0.349)$ & $(0.320)$ & & & \\
\hline \multirow[t]{2}{*}{ Italu/UK } & 1.261 & 1.544 & 5.308 & 9.387 & 1.444 & $0.77 \%$ & 0.02 \\
\hline & $(0.236)$ & $(0.283)$ & (1.863) & $(2.639)$ & & & \\
\hline \multirow[t]{2}{*}{ Iapan/UK } & 1.346 & 1.680 & 3.244 & 4.480 & 1.107 & $11.23 \%$ & 0.18 \\
\hline & $(0.086)$ & $(0.055)$ & $(0.348)$ & $(0.381)$ & & & \\
\hline \multirow[t]{2}{*}{ Canada/Iapan } & 1.407 & 0.936 & 4.539 & 3.885 & 1.287 & $6.24 \%$ & 0.09 \\
\hline & $(0.049)$ & $(0.044)$ & $(0.387)$ & $(0.262)$ & & & \\
\hline \multirow{2}{*}{ France/Iapan } & 1.678 & 1.783 & 4.346 & 3.649 & 1.265 & $14.34 \%$ & 0.14 \\
\hline & $(0.082)$ & $(0.095)$ & $(0.299)$ & $(0.171)$ & & & \\
\hline \multirow{2}{*}{ Germanu/Iapan } & 1.601 & 1.629 & 3.755 & 3.650 & 1.047 & $16.31 \%$ & 0.31 \\
\hline & $(0.055)$ & $(0.065)$ & $(0.254)$ & $(0.219)$ & & & \\
\hline \multirow[t]{2}{*}{ Italu/ Iapan } & 0.450 & 0.441 & 2.111 & 2.053 & 1.008 & $55.09 \%$ & 0.03 \\
\hline & $(0.613)$ & $(0.979)$ & $(0.149)$ & $(0.168)$ & & & \\
\hline \multirow[t]{2}{*}{ Canada/Italy } & 1.150 & 0.891 & 5.295 & 3.506 & 1.170 & $4.06 \%$ & 0.07 \\
\hline & $(0.060)$ & $(0.109)$ & $(0.718)$ & $(0.646)$ & & & \\
\hline \multirow[t]{2}{*}{ France/ Italu } & 1.288 & 1.619 & 3.567 & 4.644 & 1.036 & $6.96 \%$ & 0.03 \\
\hline & $(0.146)$ & $(0.187)$ & $(0.646)$ & $(0.795)$ & & & \\
\hline \multirow[t]{2}{*}{ Germanu/Italu } & 1.262 & 1.050 & 3.535 & 2.939 & 1.000 & $14.64 \%$ & 0.12 \\
\hline & $(0.119)$ & $(0.092)$ & $(0.472)$ & $(0.336)$ & & & \\
\hline \multirow[t]{2}{*}{ Canada/Germanu } & 1.138 & 1.137 & 3.787 & 3.840 & 1.016 & $8.06 \%$ & 0.16 \\
\hline & $(0.357)$ & $(0.191)$ & $(1.701)$ & $(1.033)$ & & & \\
\hline \multirow[t]{2}{*}{ France/Germanu } & 1.636 & 1.589 & 3.382 & 3.768 & 1.146 & $23.30 \%$ & 0.30 \\
\hline & $(0.067)$ & $(0.064)$ & $(0.150)$ & $(0.194)$ & & & \\
\hline \multirow[t]{2}{*}{ Canada/France } & 1.295 & 1.188 & 3.912 & 3.602 & 1.004 & $9.43 \%$ & 0.13 \\
\hline & $(0.111)$ & $(0.130)$ & $(0.475)$ & $(0.403)$ & & & \\
\hline
\end{tabular}

Notes: Standard errors in parentheses below coefficients. "Duration" refers to the duration of the high volatility common shock expressed in years. "Unc. Prob." refers to the unconditional probability of the high volatility regime expressed in percentage. 
Table 4. Diagnostic tests on standardized residuals and model specification

\begin{tabular}{|c|c|c|c|c|c|c|c|c|}
\hline Country pairs & $L M(1)$ & $L M(4)$ & $A R C H(1)$ & $A R C H(4)$ & Normalitu & $R C M_{1}$ & $\mathrm{RCM}_{2}$ & $R_{C} M_{3}$ \\
\hline \multirow{2}{*}{ Гanada/IS } & 5.286 & 8.194 & 3.645 & 3.747 & 0.149 & 50.17 & 32.93 & 14.43 \\
\hline & 6.472 & 9.629 & 0.178 & 0.686 & $0.310^{*}$ & & & \\
\hline \multirow{2}{*}{ Franse/l IS } & 2.052 & 8.248 & $8.781^{*}$ & $24.446^{*}$ & 0.062 & 47.53 & 34.47 & 21.68 \\
\hline & 6.512 & 11.389 & 0.010 & 1.002 & $0.275^{*}$ & & & \\
\hline \multirow[t]{2}{*}{ Germanu/l IS } & 0.738 & 5.896 & 5.450 & $28.836^{*}$ & 0.138 & 56.56 & 23.70 & 28.78 \\
\hline & 6.097 & 9.807 & 0.303 & 1.278 & $0.256^{*}$ & & & \\
\hline \multirow{2}{*}{ Italu/ISS } & 0.550 & 4.412 & 4.789 & 10.692 & $1.105^{*}$ & 61.21 & 46.85 & 19.35 \\
\hline & 6.500 & 10.058 & 0.029 & 0.741 & $0.354^{*}$ & & & \\
\hline \multirow[t]{2}{*}{ Ianan/l IS } & 0.021 & $18.621^{*}$ & $8.571^{*}$ & $45.912^{*}$ & 0.047 & 48.72 & 1.38 & 26.96 \\
\hline & 6.294 & 9.261 & 1.612 & 4.332 & $0.356^{*}$ & & & \\
\hline \multirow[t]{2}{*}{ IIKЛIS } & 1.218 & 6.593 & 0.011 & 9.564 & 0.086 & 32.49 & 49.14 & 17.06 \\
\hline & $6.763^{*}$ & 10.963 & 0.055 & 0.756 & $0.406^{*}$ & & & \\
\hline \multirow{2}{*}{ Canada/IK } & 4.439 & 6.765 & 1.029 & 1.797 & 0.113 & 36.13 & 35.79 & 14.93 \\
\hline & 1.954 & 8.586 & 0.028 & $32.713^{*}$ & 0.092 & & & \\
\hline \multirow[t]{2}{*}{ France/IIK } & 1.527 & 5.989 & 1.409 & 9.803 & $0.192^{*}$ & 33.78 & 16.95 & 30.29 \\
\hline & 0.467 & 8.023 & 0.053 & $20.162^{*}$ & 0.037 & & & \\
\hline \multirow[t]{2}{*}{ Germanu/IK } & 0.917 & 4.737 & 0.503 & $20.284^{*}$ & $0.200^{*}$ & 48.30 & 24.75 & 28.85 \\
\hline & 1.620 & 11.094 & 1.855 & $24.696^{*}$ & 0.106 & & & \\
\hline \multirow[t]{2}{*}{ Italu/ IK } & 0.772 & 3.638 & 2.982 & 5.462 & 0.098 & 49.59 & 37.22 & 1.89 \\
\hline & 1.774 & 9.785 & 0.237 & 0.843 & 0.157 & & & \\
\hline \multirow[t]{2}{*}{ Ianan/IK } & 0.000 & $18.197^{*}$ & $7.410^{*}$ & $49.955^{*}$ & 0.035 & 46.69 & 22.67 & 21.59 \\
\hline & 0.204 & 7.221 & 0.061 & 5.364 & 0.069 & & & \\
\hline \multirow[t]{2}{*}{ Canada/Ianan } & 3.881 & 6.407 & 0.764 & 1.091 & 0.118 & 36.46 & 48.01 & 13.93 \\
\hline & 0.044 & $21.110^{*}$ & 6.452 & $44.493^{*}$ & 0.052 & & & \\
\hline \multirow[t]{2}{*}{ France/Ianan } & 0.777 & 6.019 & 1.565 & $15.602 *$ & 0.151 & 40.84 & 24.06 & 30.08 \\
\hline & 0.010 & $18.044^{*}$ & 5.416 & $41.226^{*}$ & 0.068 & & & \\
\hline \multirow{2}{*}{ Germanu/Ianan } & 1.378 & 4.974 & 2.189 & $19.756^{*}$ & 0.155 & 44.01 & 14.16 & 27.70 \\
\hline & 0.049 & $20.633^{*}$ & $13.512^{*}$ & $63.177^{*}$ & 0.122 & & & \\
\hline \multirow[t]{2}{*}{ Italu/ Ianan } & 0.670 & 3.000 & 4.973 & 9.267 & 0.083 & 53.38 & 47.12 & 82.32 \\
\hline & 0.088 & 11.398 & 2.368 & $15.790^{*}$ & 0.079 & & & \\
\hline \multirow[t]{2}{*}{ Canada/Ttalı } & 4.207 & 7.414 & 0.797 & 1.628 & 0.162 & 39.65 & 57.51 & 9.77 \\
\hline & 0.760 & 5.027 & 5.050 & $11.556^{*}$ & $1.255^{*}$ & & & \\
\hline \multirow[t]{2}{*}{ Franre/ Italu } & 0.766 & 4.292 & 1.062 & $24.964^{*}$ & $0.229^{*}$ & 39.57 & 58.61 & 33.68 \\
\hline & 0.631 & 5.615 & 3.234 & 8.644 & $1.212^{*}$ & & & \\
\hline \multirow[t]{2}{*}{ Germanu/Italu } & 0.546 & 4.409 & 4.970 & $43.308^{*}$ & $0.196^{*}$ & 32.26 & 50.25 & 16.64 \\
\hline & 0.293 & 2.953 & 0.017 & 5.979 & 0.056 & & & \\
\hline \multirow[t]{2}{*}{ Canada/Crermanu } & 5.294 & 8.176 & 3.532 & 4.624 & 0.152 & 40.34 & 47.17 & 15.69 \\
\hline & 0.548 & 3.351 & $6.772^{*}$ & $14.724^{*}$ & 0.166 & & & \\
\hline \multirow[t]{2}{*}{ Franre/Germanu } & 1.331 & 8.528 & $8.351^{*}$ & $18.888^{*}$ & 0.046 & 32.72 & 41.75 & 36.02 \\
\hline & 1.880 & 6.090 & 6.605 & $47.320^{*}$ & 0.124 & & & \\
\hline \multirow[t]{2}{*}{ Canada/France } & 4.360 & 7.440 & 1.829 & 2.848 & 0.101 & 53.16 & 36.35 & 19.57 \\
\hline & 1.616 & 6.949 & $7.199 *$ & $16.364^{*}$ & 0.044 & & & \\
\hline
\end{tabular}

Notes: $\mathrm{LM}(k)$ is the Breusch-Godfrey Lagrange Multiplier test for no serial correlation up to lag $k, \mathrm{ARCH}(k)$ is the Lagrange Multiplier test for no ARCH effects of order $k$, Normality is the Cramer-von-Mises test for the null of Normality, RCMi is the Regime Classification Measure, where $\mathrm{i}=1,2,3$ for the idiosyncratic shock of the first, second and the common shock, respectively. ${ }^{*}$ denotes significance at $1 \%$ level. $\mathrm{LM}(\mathrm{k})$ and $\mathrm{ARCH}(\mathrm{k})$ have a $\chi^{2}(k)$ distribution under the null hypothesis. The Cramer-von-Mises test has a non-standard distribution and the cut-off value for RCM is 50 . 
Table 5. Likelihood ratio tests for increased comovement

\begin{tabular}{|c|c|c|c|c|c|c|c|}
\hline Market & Canada & France & Germany & Italy & Japan & UK & US \\
\hline Canada & --- & $\begin{array}{c}0.000 \\
(0.991)\end{array}$ & $\begin{array}{c}0.000 \\
(0.983)\end{array}$ & $\begin{array}{c}0.008 \\
(0.927)\end{array}$ & $\begin{array}{c}0.001 \\
(0.977)\end{array}$ & $\begin{array}{c}0.000 \\
(0.995)\end{array}$ & $\begin{array}{c}0.001 \\
(0.973)\end{array}$ \\
\hline France & & --- & $\begin{array}{l}6.219^{* *} \\
(0.013)\end{array}$ & $\begin{array}{c}0.001 \\
(0.972)\end{array}$ & $\begin{array}{c}0.193 \\
(0.660)\end{array}$ & $\begin{array}{c}0.000 \\
(0.983)\end{array}$ & $\begin{array}{c}0.354 \\
(0.552)\end{array}$ \\
\hline Germany & & & --- & $\begin{array}{c}0.000 \\
(1.000)\end{array}$ & $\begin{array}{c}0.008 \\
(0.927)\end{array}$ & $\begin{array}{c}0.001 \\
(0.972)\end{array}$ & $\begin{array}{c}0.000 \\
(0.987)\end{array}$ \\
\hline Italy & & & & --- & $\begin{array}{c}0.000 \\
(0.995)\end{array}$ & $\begin{array}{c}0.928 \\
(0.335)\end{array}$ & $\begin{array}{c}0.000 \\
(0.996)\end{array}$ \\
\hline Japan & & & & & --- & $\begin{array}{c}0.862 \\
(0.353)\end{array}$ & $\begin{array}{c}1.321 \\
(0.250)\end{array}$ \\
\hline UK & & & & & & --- & $\begin{array}{l}4.000^{* *} \\
(0.046)\end{array}$ \\
\hline US & & & & & & & ---- \\
\hline
\end{tabular}

Notes: Likelihood ratio statistic is for the null of no increased comovement against the alternative of increased comovement for the indicated country pairs. The test statistic has a $\chi^{2}(1)$ distribution under the null hypothesis. ${ }^{* * *}$ denotes significance at $1 \%$ level, ${ }^{* *}$ denotes significance at $5 \%$ level, and ${ }^{*}$ denotes significance at $10 \%$ level. $p$-values are reported in parentheses below coefficients. 
Table 6. Estimates of impact coefficients of idiosyncratic shocks

\begin{tabular}{|c|c|c|c|c|c|c|}
\hline Country pairs & $\delta_{1}$ & $\delta_{2}$ & $\delta_{1}^{*}$ & $\delta_{2}^{*}$ & $\begin{array}{c}\text { Unc. Prob./ } \\
\text { Duration } \\
\text { (1) }\end{array}$ & $\begin{array}{l}\text { Unc. Prob./ } \\
\text { Duration (2) }\end{array}$ \\
\hline \multirow[t]{2}{*}{ Canada/I IS } & 0.898 & 0.704 & 1.924 & 1.754 & $36.06 \%$ & $33.03 \%$ \\
\hline & $(0.140)$ & $(0.200)$ & $(0.158)$ & $(0.113)$ & 0.52 & 1.62 \\
\hline \multirow[t]{2}{*}{ France/l IS } & 1.767 & 0.037 & 3.708 & 1.500 & $29.26 \%$ & $66.55 \%$ \\
\hline & $(0.060)$ & $(0.102)$ & $(0.213)$ & $(0.091)$ & 0.25 & 4.93 \\
\hline \multirow[t]{2}{*}{ Germanu/l IS } & 1.455 & 1.259 & 2.753 & 2.656 & $39.65 \%$ & $16.64 \%$ \\
\hline & $(0.121)$ & $(0.026)$ & $(0.112)$ & $(0.150)$ & 0.48 & 1.07 \\
\hline \multirow[t]{2}{*}{ Italu/l IS } & 1.722 & 1.075 & 3.657 & 2.163 & $46.55 \%$ & $34.87 \%$ \\
\hline & $(0.092)$ & $(0.067)$ & $(0.153)$ & $(0.126)$ & 0.25 & 1.17 \\
\hline \multirow{2}{*}{ Ianan/l IS } & 1.728 & 1.524 & 4.108 & 10.147 & $49.25 \%$ & $0.54 \%$ \\
\hline & (0.117) & $(0.050)$ & $(0.154)$ & (3.321) & 0.53 & 0.03 \\
\hline \multirow[t]{2}{*}{ I IKЛ IS } & 1.549 & 0.827 & 3.495 & 1.881 & $23.86 \%$ & $47.19 \%$ \\
\hline & $(0.082)$ & $(0.139)$ & (0.191) & $(0.119)$ & 0.46 & 1.36 \\
\hline \multirow[t]{2}{*}{ Canada/IK } & 1.128 & 1.527 & 2.204 & 3.516 & $21.39 \%$ & $25.24 \%$ \\
\hline & $(0.089)$ & $(0.105)$ & $(0.236)$ & $(0.225)$ & 0.98 & 0.42 \\
\hline \multirow{2}{*}{ France/l IK } & 1.338 & 0.752 & 3.674 & 2.255 & $19.08 \%$ & $45.13 \%$ \\
\hline & $(0.136)$ & $(0.166)$ & $(0.282)$ & $(0.099)$ & 0.26 & 7.75 \\
\hline \multirow{2}{*}{ Germanu/IK } & 0.768 & 1.048 & 2.088 & 2.794 & $51.57 \%$ & $44.66 \%$ \\
\hline & $(0.143)$ & $(0.138)$ & $(0.059)$ & $(0.092)$ & 1.19 & 2.65 \\
\hline \multirow[t]{2}{*}{ Italu/l IK } & 1.742 & 0.531 & 3.337 & 2.173 & $62.67 \%$ & $49.48 \%$ \\
\hline & $(0.064)$ & $(0.889)$ & $(0.261)$ & $(0.198)$ & 1.00 & 1.51 \\
\hline \multirow[t]{2}{*}{ Ianan/IK } & 1.743 & 0.045 & 3.949 & 2.094 & $52.09 \%$ & $53.87 \%$ \\
\hline & $(0.081)$ & $(0.113)$ & $(0.157)$ & (0.113) & 0.61 & 6.20 \\
\hline \multirow{2}{*}{ Canada/Ianan } & 0.984 & 2.034 & 2.152 & 4.326 & $26.52 \%$ & $44.50 \%$ \\
\hline & $(0.032)$ & $(0.092)$ & $(0.212)$ & $(0.118)$ & 1.37 & 0.46 \\
\hline \multirow[t]{2}{*}{ France/Ianan } & 0.984 & 0.484 & 2.796 & 3.201 & $38.15 \%$ & $74.14 \%$ \\
\hline & (0.009) & $(0.190)$ & $(0.201)$ & $(0.106)$ & 1.26 & 2.64 \\
\hline \multirow{2}{*}{ Germanu/Ianan } & 0.729 & 0.674 & 2.190 & 3.453 & $44.01 \%$ & $59.56 \%$ \\
\hline & $(0.162)$ & $(0.155)$ & $(0.070)$ & $(0.074)$ & 1.32 & 8.11 \\
\hline \multirow[t]{2}{*}{ Italu/Ianan } & 1.402 & 1.627 & 3.379 & 3.874 & $59.40 \%$ & $43.45 \%$ \\
\hline & $(0.082)$ & $(0.169)$ & $(0.161)$ & $(0.190)$ & 0.60 & 0.53 \\
\hline \multirow[t]{2}{*}{ Canada/talı } & 1.297 & 1.613 & 2.466 & 3.508 & $25.12 \%$ & $51.96 \%$ \\
\hline & $(0.088)$ & $(0.057)$ & $(0.173)$ & $(0.124)$ & 0.80 & 0.35 \\
\hline \multirow[t]{2}{*}{ France/Italu } & 1.220 & 1.074 & 2.767 & 3.028 & $45.77 \%$ & $62.63 \%$ \\
\hline & $(0.140)$ & $(0.245)$ & $(0.167)$ & $(0.156)$ & 2.58 & 0.82 \\
\hline \multirow[t]{2}{*}{ Germanu/Italu } & 1.150 & 1.436 & 2.423 & 3.318 & $43.19 \%$ & $52.36 \%$ \\
\hline & $(0.093)$ & $(0.126)$ & $(0.208)$ & $(0.137)$ & 2.04 & 0.34 \\
\hline \multirow[t]{2}{*}{ Canada/Cегтаnи } & 1.305 & 1.462 & 2.524 & 2.961 & $23.77 \%$ & $29.97 \%$ \\
\hline & $(0.152)$ & $(0.250)$ & $(0.677)$ & $(0.215)$ & 0.52 & 0.41 \\
\hline \multirow[t]{2}{*}{ France/Germanu } & 0.848 & 0.003 & 2.935 & 1.476 & $40.89 \%$ & $73.43 \%$ \\
\hline & $(0.053)$ & $(0.020)$ & $(0.114)$ & $(0.070)$ & 0.78 & 2.02 \\
\hline \multirow{2}{*}{ Canada/France } & 1.093 & 1.755 & 2.126 & 3.711 & $30.41 \%$ & $25.63 \%$ \\
\hline & $(0.081)$ & $(0.110)$ & $(0.200)$ & $(0.221)$ & 0.62 & 0.50 \\
\hline
\end{tabular}

Notes: Standard errors in parentheses below coefficients. "Duration" refers to the duration of the high volatility regime of the idiosyncratic shock expressed in years. "Unc. Prob." refers to the unconditional probability of the high volatility regime expressed in percentage. 
Table 7. Risk reduction benefits accruing to international diversification

\begin{tabular}{|c|c|c|c|c|c|c|}
\hline$x \%$ & Canada & France & Germany & Italy & Japan & UK \\
\hline \multicolumn{7}{|c|}{ Panel A } \\
\hline 5 & $3.0 \%$ & $4.2 \%$ & $5.3 \%$ & $6.3 \%$ & $5.3 \%$ & $4.4 \%$ \\
\hline 10 & $5.5 \%$ & $7.4 \%$ & $9.8 \%$ & $11.5 \%$ & $9.1 \%$ & $8.0 \%$ \\
\hline 15 & $7.8 \%$ & $9.7 \%$ & 13.6 & $15.2 \%$ & $11.2 \%$ & $10.8 \%$ \\
\hline 20 & $9.6 \%$ & $11.1 \%$ & $16.5 \%$ & $17.8 \%$ & $11.7 \%$ & $12.8 \%$ \\
\hline 25 & $11.1 \%$ & $11.5 \%$ & $18.7 \%$ & $19.2 \%$ & $10.5 \%$ & $14.0 \%$ \\
\hline \multicolumn{7}{|c|}{ Panel B } \\
\hline 5 & $0 \%$ & $0 \%$ & $0 \%$ & $0 \%$ & $0 \%$ & $0 \%$ \\
\hline 10 & $0 \%$ & $0 \%$ & $0 \%$ & $0 \%$ & $0 \%$ & $0 \%$ \\
\hline 15 & $0 \%$ & $2 \%$ & $0 \%$ & $0 \%$ & $0 \%$ & $0 \%$ \\
\hline 20 & $0 \%$ & $6 \%$ & $0 \%$ & $0 \%$ & $5 \%$ & $3 \%$ \\
\hline 25 & $0 \%$ & $15 \%$ & $0 \%$ & $1 \%$ & $21 \%$ & $7 \%$ \\
\hline
\end{tabular}

Notes: Panel A presents the average risk reduction achieved by a US investor who holds $\mathrm{x} \%$ of funds in the foreign asset and the remainder in domestic equity. Panel B reports the proportion of time that the diversified portfolio is more risky than the US portfolio. 
Table 8. Estimates of impact coefficients of common shocks (local currency)

\begin{tabular}{|c|c|c|c|c|c|c|c|}
\hline Country pairs & $\delta_{c 1}$ & $\delta_{c 2}$ & $\delta_{c 1}^{*}$ & $\delta_{c 2}^{*}$ & $r$ & $L R$. & $p$-val \\
\hline Canada/US & $\begin{array}{c}1.080 \\
(0.025)\end{array}$ & $\begin{array}{c}1.667 \\
(0.033)\end{array}$ & $\begin{array}{c}1.961 \\
(0.077)\end{array}$ & $\begin{array}{c}3.325 \\
(0.072)\end{array}$ & 1.099 & $2.784^{*}$ & 0.095 \\
\hline France/US & $\begin{array}{c}1.424 \\
(0.192)\end{array}$ & $\begin{array}{c}1.187 \\
(0.075)\end{array}$ & $\begin{array}{c}3.446 \\
(0.742)\end{array}$ & $\begin{array}{c}3.930 \\
(0.475)\end{array}$ & 1.368 & 0.000 & 1.000 \\
\hline Germany/US & $\begin{array}{c}1.020 \\
(0.004)\end{array}$ & $\begin{array}{c}0.832 \\
(0.056)\end{array}$ & $\begin{array}{c}3.060 \\
(0.184)\end{array}$ & $\begin{array}{c}2.507 \\
(0.166)\end{array}$ & 1.004 & 0.000 & 0.996 \\
\hline Italy/US & $\begin{array}{c}0.671 \\
(0.060)\end{array}$ & $\begin{array}{c}1.219 \\
(0.029)\end{array}$ & $\begin{array}{c}2.171 \\
(0.266)\end{array}$ & $\begin{array}{c}4.045 \\
(0.321)\end{array}$ & 1.026 & 0.000 & 0.994 \\
\hline Japan/US & $\begin{array}{c}1.374 \\
(0.019)\end{array}$ & $\begin{array}{c}0.671 \\
(0.010)\end{array}$ & $\begin{array}{c}1.851 \\
(0.388)\end{array}$ & $\begin{array}{c}2.473 \\
(0.242)\end{array}$ & 2.736 & 1.156 & 0.282 \\
\hline UK/US & $\begin{array}{c}1.078 \\
(0.071)\end{array}$ & $\begin{array}{l}1.259 \\
(0.056)\end{array}$ & $\begin{array}{c}3.266 \\
(0.317)\end{array}$ & $\begin{array}{c}3.816 \\
(0.303)\end{array}$ & 1.000 & 0.000 & 0.996 \\
\hline Canada/UK & $\begin{array}{c}0.921 \\
(0.054)\end{array}$ & $\begin{array}{c}1.421 \\
(0.058)\end{array}$ & $\begin{array}{c}2.041 \\
(0.191)\end{array}$ & $\begin{array}{c}4.963 \\
(0.312)\end{array}$ & 1.576 & $2.941^{*}$ & 0.086 \\
\hline France/UK & $\begin{array}{c}1.420 \\
(0.068)\end{array}$ & $\begin{array}{c}1.334 \\
(0.037)\end{array}$ & $\begin{array}{c}4.802 \\
(0.399)\end{array}$ & $\begin{array}{c}4.545 \\
(0.340)\end{array}$ & 1.007 & 0.011 & 0.916 \\
\hline Germany/UK & $\begin{array}{c}0.577 \\
(0.074)\end{array}$ & $\begin{array}{c}1.469 \\
(0.045)\end{array}$ & $\begin{array}{c}3.095 \\
(0.192)\end{array}$ & $\begin{array}{c}2.412 \\
(0.133)\end{array}$ & 3.267 & $10.793^{* * *}$ & 0.001 \\
\hline Italy/UK & $\begin{array}{c}0.719 \\
(0.124)\end{array}$ & $\begin{array}{c}0.805 \\
(0.117)\end{array}$ & $\begin{array}{c}2.411 \\
(0.247)\end{array}$ & $\begin{array}{c}2.716 \\
(0.434)\end{array}$ & 1.006 & 0.000 & 0.986 \\
\hline Japan/UK & $\begin{array}{c}1.306 \\
(0.091)\end{array}$ & $\begin{array}{c}1.321 \\
(0.044)\end{array}$ & $\begin{array}{c}3.655 \\
(0.905)\end{array}$ & $\begin{array}{c}4.812 \\
(0.361)\end{array}$ & 1.302 & $6.898^{* * *}$ & 0.009 \\
\hline Canada/Japan & $\begin{array}{c}1.024 \\
(0.162)\end{array}$ & $\begin{array}{c}1.157 \\
(1.067)\end{array}$ & $\begin{array}{c}4.003 \\
(1.348)\end{array}$ & $\begin{array}{c}4.617 \\
(0.386)\end{array}$ & 1.021 & $6.483^{* * *}$ & 0.011 \\
\hline France/Japan & $\begin{array}{c}1.594 \\
(0.061)\end{array}$ & $\begin{array}{c}1.511 \\
(0.094)\end{array}$ & $\begin{array}{c}4.410 \\
(0.340)\end{array}$ & $\begin{array}{c}3.876 \\
(0.301)\end{array}$ & 1.079 & 0.025 & 0.874 \\
\hline Germany/Japan & $\begin{array}{c}0.383 \\
(0.051)\end{array}$ & $\begin{array}{c}2.885 \\
(0.091)\end{array}$ & $\begin{array}{c}2.905 \\
(0.652)\end{array}$ & $\begin{array}{c}3.159 \\
(0.145)\end{array}$ & 6.927 & $44.648^{* * *}$ & 0.000 \\
\hline Italy/Japan & $\begin{array}{c}1.428 \\
(0.051)\end{array}$ & $\begin{array}{c}0.683 \\
(0.099)\end{array}$ & $\begin{array}{c}8.887 \\
(2.697)\end{array}$ & $\begin{array}{c}0.698 \\
(0.177)\end{array}$ & 6.090 & 0.760 & 0.383 \\
\hline Canada/Italy & $\begin{array}{c}0.904 \\
(0.038)\end{array}$ & $\begin{array}{c}0.696 \\
(0.099)\end{array}$ & $\begin{array}{c}4.196 \\
(0.717)\end{array}$ & $\begin{array}{c}2.895 \\
(0.467)\end{array}$ & 1.116 & 0.000 & 1.000 \\
\hline France/Italy & $\begin{array}{c}0.572 \\
(0.073)\end{array}$ & $\begin{array}{c}1.035 \\
(0.046)\end{array}$ & $\begin{array}{c}1.247 \\
(0.114)\end{array}$ & $\begin{array}{c}2.679 \\
(0.111)\end{array}$ & 1.187 & 0.000 & 1.000 \\
\hline Germany/Italy & $\begin{array}{c}0.675 \\
(0.234)\end{array}$ & $\begin{array}{c}0.613 \\
(0.104)\end{array}$ & $\begin{array}{c}2.352 \\
(0.142)\end{array}$ & $\begin{array}{c}2.113 \\
(0.163)\end{array}$ & 1.011 & 0.000 & 1.000 \\
\hline Canada/Germany & $\begin{array}{c}1.189 \\
(0.099)\end{array}$ & $\begin{array}{c}0.637 \\
(0.069)\end{array}$ & $\begin{array}{c}1.934 \\
(0.114)\end{array}$ & $\begin{array}{c}2.862 \\
(0.161)\end{array}$ & 2.762 & $3.710^{*}$ & 0.054 \\
\hline France/Germany & $\begin{array}{c}1.459 \\
(0.064)\end{array}$ & $\begin{array}{c}1.073 \\
(0.070)\end{array}$ & $\begin{array}{c}3.189 \\
(0.172)\end{array}$ & $\begin{array}{c}3.504 \\
(0.149)\end{array}$ & 1.494 & $2.707^{*}$ & 0.100 \\
\hline Canada/France & $\begin{array}{c}0.953 \\
(0.124) \\
\end{array}$ & $\begin{array}{c}1.254 \\
(0.215) \\
\end{array}$ & $\begin{array}{c}2.748 \\
(0.240) \\
\end{array}$ & $\begin{array}{c}3.599 \\
(0.278) \\
\end{array}$ & 1.005 & 0.000 & 0.987 \\
\hline
\end{tabular}

Notes: Columns and tests defined as in Table 5. 
Figure 1. Filter Probabilities of high volatility idiosyncratic shocks
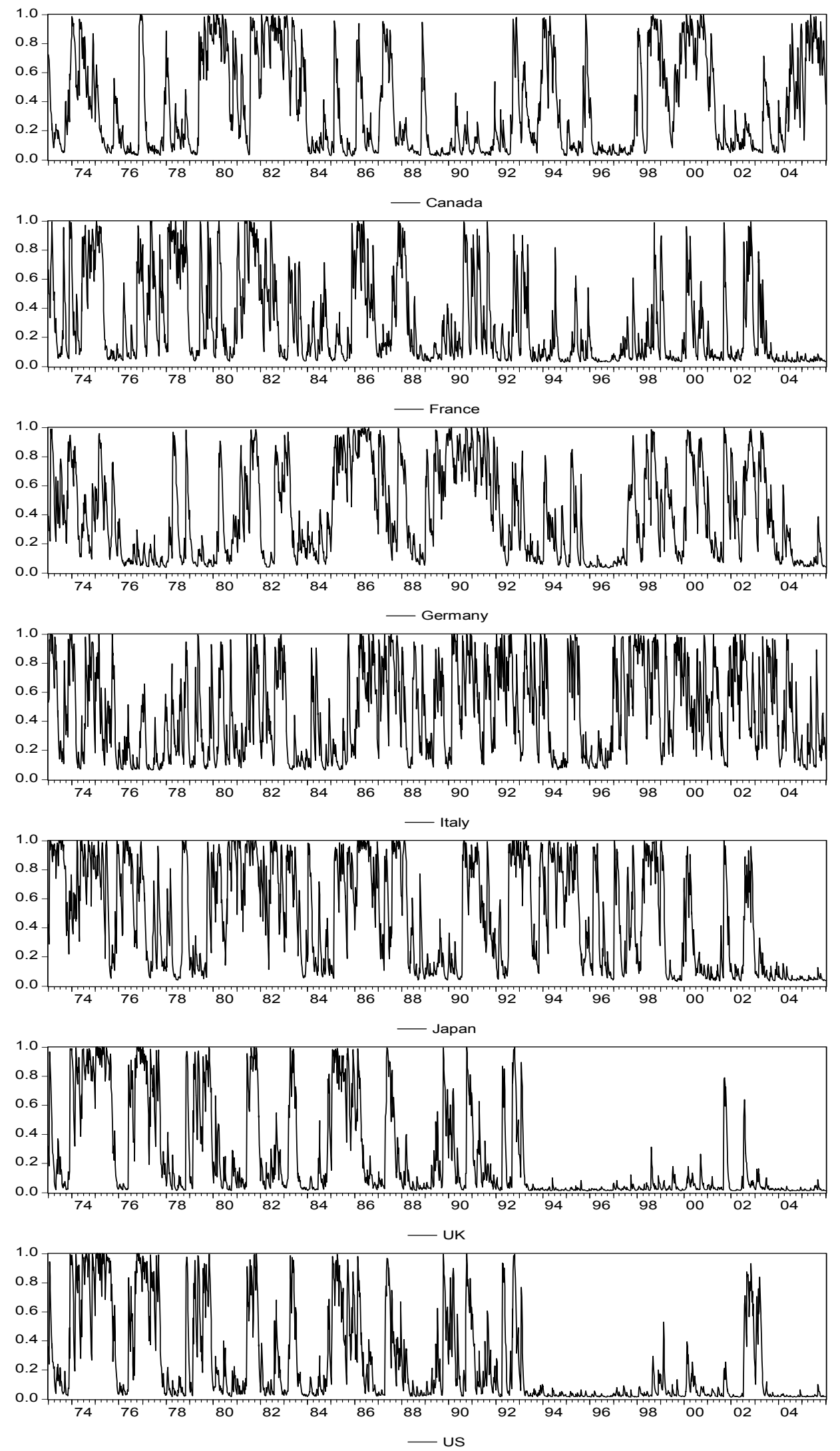
Figure 2. Filter probabilities of high volatility common shocks
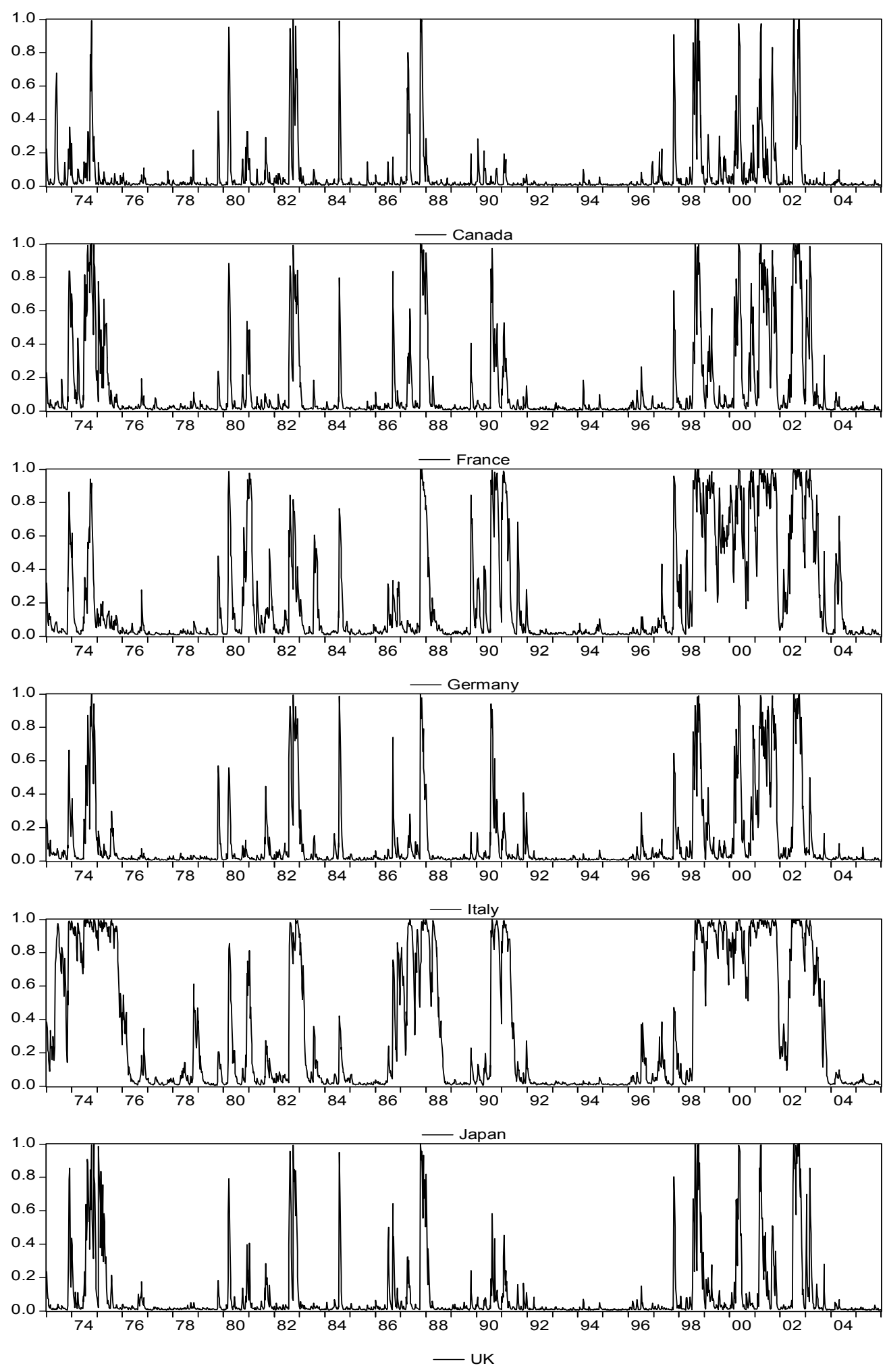
Figure 3. Risk reduction benefits from international diversification
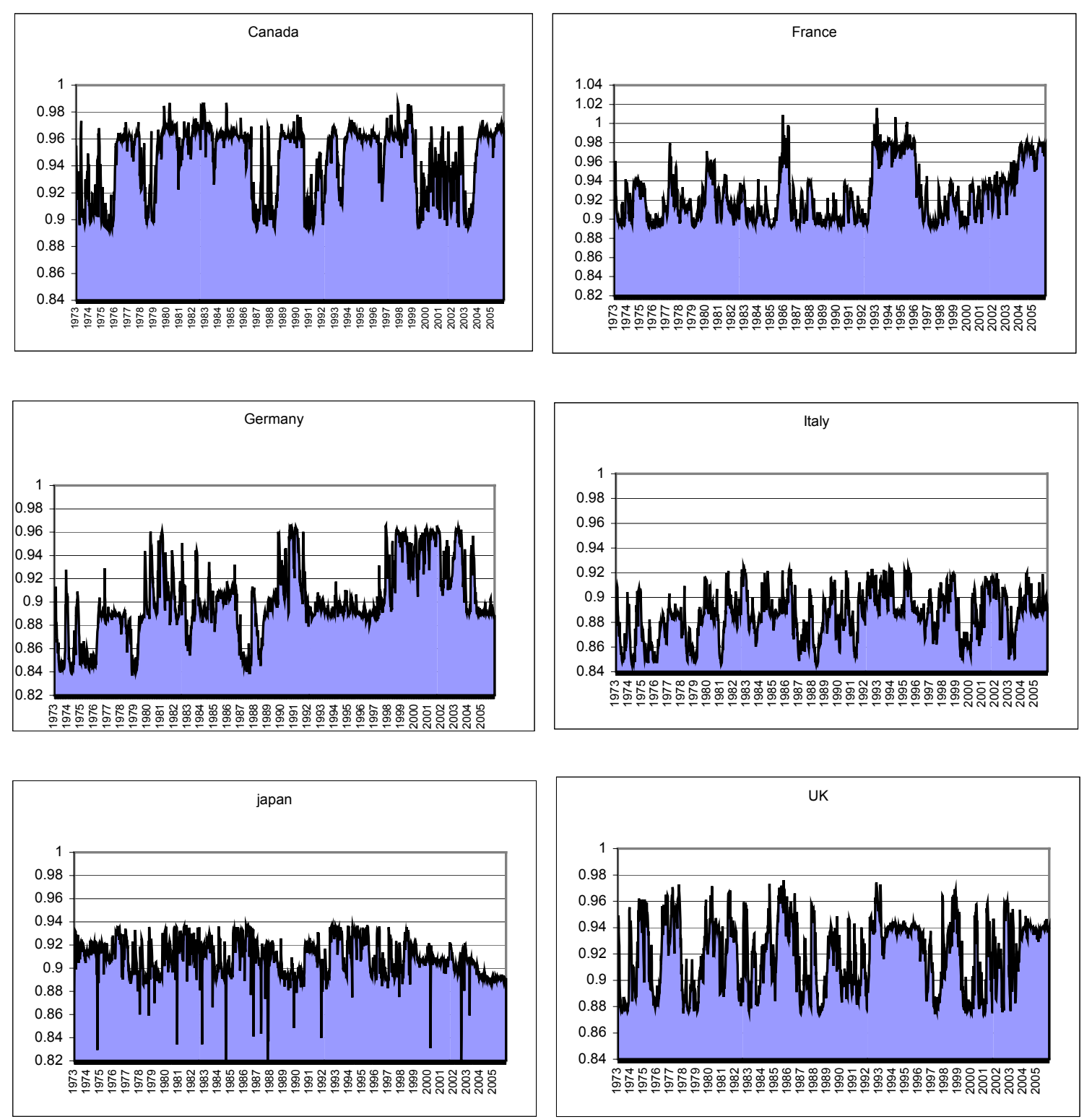